\title{
Evaluation and Comparison of Performance in the Disc Filter with Sand Filters of Filtration Equipment in Micro Irrigation Systems
}

\author{
Masoud Ghaffari ${ }^{1} \&$ Jaber Soltani ${ }^{2}$ \\ ${ }^{1}$ M.Sc of Irrigation \& Drainage Eng., Dept. of Water Eng., University of Tehran, Iran \\ ${ }^{2}$ Assistant Professor of Dept. of Water Eng., College Of Abureyhan, University of Tehran, Iran \\ Correspondence: Jaber Soltani, E-mail: jsoltani@ut.ac.ir \\ Received: December 9, 2015 \\ Accepted: July 13, 2016 \\ Online Published: July 19, 2016 \\ doi:10.5539/mas.v10n8p264 \\ URL: http://dx.doi.org/10.5539/mas.v10n8p264
}

\begin{abstract}
At the present time, the need to evacuate organic and green growth of algae contaminants in micro irrigation system is expanding increasingly. The worldwide populace is expanding and as a result of this, the world may encounter extraordinary fresh water shortage. Our water assets are constrained and, subsequently, water treatment and reusing strategies are the main choices for getting crisp and fresh water in the coming decades. This study examines the rate of the impact of green growth of algae existing in micro irrigation system performance on the disc filters and sand tanks in the examination field of water, soil and horticultural and agricultural commercial enterprises Vice-Presidency of Karaj.

The analyses were performed in four scenarios comprising of ordinary disc filter together with sand tank, automated disc filter together with sand tank, automated disc filter without sand tank lastly common ordinary disc filter without sand tank. These scenarios were assessed and looked at in three classifications of physical quality of irrigation system water. Data collection and experiments was run up to three months. The results of the experiments demonstrated that concentration of organic and suspended materials is viewed as safe for low flow emitters. In the range of 50 through $100 \mathrm{mg}$ per liter, automated disc filters represented a good performance. In the concentration of $100 \mathrm{mg} / \mathrm{l}$ or higher, the performance of disc filters significantly decreased; subsequently it is important to put the sand tank before disc filters.
\end{abstract}

Keywords: automated, sand tank, central control, micro irrigation, algae

\section{Introduction}

Because of restricted water assets in the arid and semi-arid lands, Irrigation systems having high efficiency are utilized for agricultural products. Among the irrigation systems utilized today, trickle irrigation system is one of the most effective strategies. A successive issue in this sort of irrigation system framework is the clogging of emitters, which is specifically identified with water quality and filtering system framework efficiency. Regularly, obstacles are brought about by a mix of physical, bio-chemical components present in the irrigation system water. All these require that we develop cost effective and efficient filters to reuse and recycle the water.

The suspended solid (SS) level in water is, therefore, one of the most important determinants of clogging. There have been attempts to recommend acceptable levels of SS concentration in RWI schemes (Bucks et al., 1979 \& Boswell et al., 1990). These recommended values also vary with the size of the drippers. In case of emitters with shorter and wider labyrinths, the acceptable limit of SS that leadsto minor clogging hazard can be increased to as high as $200 \mathrm{mg} / \mathrm{l}$, in case of inefficiency of central control system, the risk of emitters' blockage increases and hence design and the implementation of drip irrigation systems faces serious limitations (Capra \& Scicolone, 1998) and the main problems of drip irrigation systems in the province can be classified in four main categories based on, design, implementation, management and operation of social and natural division, in each of which the most important are design and improper implementation, lack of cleaning filters, clogging and improper number of emitters, not-adjustment of inlet valve on manifold, inappropriate pressure and its nonuniform distribution, low wetted area and extreme weakness in operation management by the users (Shaker et al., 2014).

In order to investigate the reasons of decrease in blockage outcome of most outputs and improper performance of mesh and sand filters, the drip irrigation systems implemented in Ferdous region, Ghain and Birjand were assessed and it was found that the primary purpose behind unavoidable losses in blockage result of most yields 
and their undesirable execution is improper performance of the screen and sand filters because of non-filtration of used water in the system (Najafi mod et al., 2007).

In another survey, the hydraulic performance of drip irrigation using wastewater was studied. The first subunit included a 130 micrometer disc filter; the second subunit included a 130 micrometer screen filter where both subunits were evaluated with secondary wastewater from active slime. The third subunit included a 130 micrometer screen filer with wastewater filtrated by sand particles and were disinfected. The results showed that the performance of emitters in secondary wastewater decreased significantly in contrast to the filters which had a better performance in the third subunit (Bargués et al., 2005). In a trial, the performance of sand and disc filters was assessed in the central control part where low quality water had been utilized for irrigation system.

Since the loss of pressure in various water flows and the rate of suspended materials in various pressures of disc filters was lower contrasted with sand filters, furthermore there is no collision of layers in these (disc) filters, consequently the execution of disc filters was better compared to the sand filters (Alikhani and Zarei, 2010). In another evaluation, the fast growth of biofilm and reposition of residue in the entry of emitters were viewed as the other stimulating components of blockage (Yan et al., 2010). In another study, the investigation and evaluation of three sand filter models were performed. Therefore the experiments were performed in two parts. The first part investigated the effect of inner elements (just sand filters) on the head loss for the specified direction of the water passage at the same time with filtration processes and inverse wash-up, and the second part found that the values of water head loss are significantly produced by sand particles inside tank, bed depth, velocity of filtration and the mutual effects between these variables (Mesquita et al., 2012).

The aim of this work was to evaluate the rate of the effect of algae existing in irrigation water on the performance of the disc filters together with sand tank without sand tank in the central control system and selection of the best composition of this equipment in different qualities of irrigation water.

\section{Method}

Keeping in mind the end goal and in order to investigate and evaluate the central control system and the performance of filters in different qualities of water, a central control system consisting of a 50-200 centrifugal pump , a sand filter apparatus and an automated self-wash disc filter apparatus were installed in the research filed of water, soil and agricultural industries Vice-Presidency of Karaj.

For sand filters first of all, silica particles were isolated by sieves with appropriate mesh and were accommodated inside a tank. The sieves included a sieve no. 5 and a sieve no. 7. The particles remaining in sieve no. 5 were silica larger particles and the particles remaining in sieve no. 7 were average sized particles of silica, and the particles passing through both sieves were considered small particles. After the particles isolation, the sands entered the tank in a way that a thin layer of larger particles were scattered on the floor of the tank as retention. Then the first layer the small sized particles, the second layer average sized particles and finally larger sized particles, were placed inside the tank. The height of all the silica cluttered inside the sand filters was a total of Two-thirds of the tank height. As a whole the height of filtration tank was 150 centimeters and according to the above mentioned notes, total height of silica grains inside the tank was 100 centimeters and the above height of the tank was left vacant. automated disc filter included a central control unit which controlled the automated wash-up of filters, and also two Azud Helix red disc filters of 130 micron was placed in the passage of the system. The water in the considered reservoir as indicated by the atmosphere conditions and climate temperature involved the variety of concentrations of plant organics and algae. Thus in this study, the irrigation system water with assortment of concentrations of plant organics and algae and suspended particles introduced in table 3 .

Water irrigation enters the central control system through pumping system, and then four subunits were selected in central control part for evaluating the system performance as follows. The subunits included sand tank and ordinary disc filter, sand tank together with self-wash automated disc filter; self-wash automated disc filter without sand tank, and finally ordinary disc filter without sand tank.

Amid the examination on each of the subunits, diverse parameters incorporating pressure in various parts of filtration, water flow discharging from filtration framework, blockage time duration of filters, and the rate of particles passing through filtrated and filtration apparatus were measured. With a specific end goal to calculate the rate of particles separated from the equipment and determine the filtration percent of every subunit, foremost the weight of dry filter papers was weighed in a sensitive and delicate scale, and afterward a liter of irrigation water before going into filtration system was taken by a beaker, and poured onto a filter paper. The filter paper was taken carefully and left for several days in the laboratory temperature ( 25 degrees centigrade) to dry and then the filter paper was weighed again. The difference of filter paper weight in the two stages represented the weight of suspended material in sample water with 1 liter volume. As such a sample of water emitting from the 
central control system was taken and the amount of suspended material was calculated and filtration percentage in each experiment was determined. In order to clarify total steps of experiments, figure 1 is illustrated in a flowchart.

In deciding the rate of water loss amid filters cleanup operation, the time length of filter blockage was recorded in every trial. The introduced counters in system represented the rate of water passing the system in the unit of $\mathrm{m}^{3}$

Therefore according to the system operation time length, the passing water flow was calculated and measured. Also during the experiments, duration of sand tank blockage and disc filters and the rate of primary pressure loss in system were recorded. For pressure loss of 3.5 meters, tank wash-up operation was performed and for seven meters pressure loss according to the considered standard, disc filter wash-up operation was performed and the amount of water consumed was recorded. Also the rate of loss of water flow passing the system and production capacity loss in pump shaft due to blockages in sand tank was calculated by equation (1).

$$
\mathrm{Na}=\frac{\rho g Q H}{\eta}
$$

In this equation, $\boldsymbol{\rho}$ is water density $\left(\mathrm{kg} / \mathrm{m}^{3}\right), \mathrm{g}$ is Gravity of Earth, $\mathrm{Q}$ is the water flow passing the $\operatorname{pump}\left(\mathrm{m}^{3} / \mathrm{s}\right), \mathrm{H}$ is the equivalent height of the pressure emitting from pump $(\mathrm{m})$. In this study, data analyzes based on the filters blockage times in different qualities of water inside the channel and the amount of water for wash-up was performed in order to determine the possibility of sand tank emission during disc filter usage by hand wash or automated wash-up in a suitable quality. Data analyzes was performed by illustrative diagrams using EXCEL software.

\section{Results}

The blockage duration of disc filters in irrigation water quality with slight for subunits inclusive of sand tank and without sand tank were compared. The blockage duration of disc filters in both subunits were compared together. According to tables 2 and 3, the blockage duration of disc filters in both subunits were almost equal and in about 300 through 320 minutes, a seven meter pressure loss was achieved. In experiments regarding subunits without sand tank, the pressure entering the disc filter was equal to the pressure exiting pump and had a constant value of 40 meters. The outcomes of the accompanying investigations for comparing both subunits demonstrated that quality of irrigation water was with moderate and the concentration of organic and suspended materials was 50 through $100 \mathrm{mg} / \mathrm{liter}$. As the figures 2 and 3 represent, the blockage duration of disc filters without sand tank was an average of about 100 minutes, whereas the average of blockage duration with sand tank was about 180 through 200 minutes. The reason for this time difference is that without sand tank, all algae move towards disc filters and surround disc filter and decrease filter blockage time duration. But with sand tank, larger particles of algae are taken by sand tank, and small sized particles enter into disc filter and these particles are easily washable automatically.

As such the measured particles include: pressure in exiting point, water flow passing at the end of exiting point, the rate of particles passing through filtration equipment and remained in filter paper for all subunits are totally provided in table 4.

Finally the subunits in lower quality of irrigation water with severe limitation where contamination concentration was more than 100 milligram/ liter were compared together. Therefore disc filters without sand tank were quickly blocked and a pressure loss of seven meter occurred in about 15 through 20 minutes.

Additionally, because of more reposition of algae entering the surroundings of disc filters, the automated wash-up system was not capable of washing and separating of particles from filter surface and as Figure 4 demonstrates. The filters that are obstructed after automated wash-up and a pressure loss occurs in the system. In this manner, disc filter clean up ought to be by hand so that all the algae stuck to the filters get to be secluded.

Then the sand tank is added to the system. In this case the blockage duration of disc filters increase from 10 to 45 through 50 minutes. Therefore part of the algae is isolated by sand tank and these results in blockage duration of disc filters.

The rate of suspended materials in the water entering the filtration system and exiting the system in 36 experiments was measured and the results are provided in figures 5 . As it is seen, in most cases the rate of suspended materials in filtrated water is less than 30 milligram/liter. Also the filtration percentage was about 75 through 85 percent for all the experiments.

Considering the measurements, sand tank is blocked every eight hours in average which caused two to three 
meters loss. Therefore it required wash-up and the rate of water loss for tank wash-up was estimated about 0.5 $\mathrm{m}^{3}$. Also in these conditions, due to blockage and a three meters loss in sand tank, the water flow entering the system decreased about 0.7 liter/seconds and resulted in 15 percent loss in production capacity of pump shaft.

\section{Discussion}

In the wake of examining the performance of filters in every treatment as per the outcomes acquired, the results of their performance are given in table 5. As it is clear from the table, top performance is indicated by a check mark icon (), and the poor performance of the system is shown with an asterisk ( ).

According to the experiments and comparison of subunits, it is clear that in contamination percent of less than 50 $\mathrm{mg} /$ liter, disc filters without sand tank showed a good performance.

Disc filters in concentration range of 50 through 100 milligram/liter had a good performance and its performance can be improved by adding sand tank. And in concentrations higher than $100 \mathrm{mg} / \mathrm{l}$, the performance of disc filters significantly decreases and the presence of sand tank is necessary. Therefore if the contamination rate is in high or average limitation, the primary filtration of the water inside the channel is necessary in order to improve the performance of disc filters. This primary filtration could be of sand tank in order to isolate larger sized particles of algae from irrigation water in a way that no disorder occurs in the performance of disc filters.

\section{Acknowledgements}

This article is extracted from master's thesis of Massoud Ghaffari. The authors would like to thank Professor Ali Rahimikhoob and Dr Mehdi Akbari for their support and guidance of this thesis.

\section{References}

Alikhani, H., \& Zarei, R. (2010). The application of drip irrigation and the effect of sand filters and disk performance. Proceedings of National Conference of water, soil, plants and agricultural mechanization: 1-2 Mars., IAU Dezful Branch.

Bucks, D. A., Nakayama, F. S., \& Gilbert, R. G. (1979). Trickle irrigation water quality and preventive maintenance. Agricultural Water Management, 2(2), pp. 149-162.

Boswell, M. (1990). Micro-irrigation Design Manual. James Hardie Irrigation: El Cajon, California, 3(1)-9(5).

Capra A, Scicolone, B. (1998). Water quality and distribution uniformity in drip/trickle irrigation systems. Journal of Agricultural Engineering Research, 70, 355-65.

Ghassemi, A., Danesh, S., \& Alizadeh, A. (2012). Feasibility Study of Using Drip System in Irrigation with Effluent fromWastewater Treatment Plants in Mashhad. Iranian Journal of lrrigation and drainage, 6(3), 152-162.

Mesquita, M., Testezlaf, R., \& Ramirez, J. C. S. (2012). The effect of media bed characteristics and internal auxiliary elements on sand filter head loss. Journal of Agricultural Water Management, 115(2012), 178- 185.

Najafimod, H., Montazar, A., Bahrani, M. (2007). The Evaluation of sprinkle irrigation systems in south khorasan. Journal of Agric. Sci. Nature, 14(1), 12-26.

Puig, B. J., Arbat, G., Barragan, J., \& Cartagena, F. (2005). Hydraulic performance of drip irrigation subunits using WWTP effluents. Journal of Agricultural Water Management, 77(2005), 249-262.

Shaker, M., Hesam, M., Kiani, A., \& Zakeri, N. M. (2014). Technical evaluation of implemented drip irrigation systems in the gardens of Golestan Province. J. of Water and Soil Conservation, 21(4).

Technical and Criteria Pressurized Irrigation Methods. (1998). Office improve irrigation techniques. Deputy Industry and infrastructure. Ministry of Agriculture. First Edition. The Head Office of the development of pressurized irrigation. p116.

Yan, D., Yang, P., Rowan, M., Ren, S., \& Pitts, D. (2010). Biofilm accumulation and Structure in the Flow Path of drip emitter using reclaimed wastewater. Journal of American Society of Agricultural and Biological Engineers, 53(3), 751- 758. 


\section{Appendix}

Tables and Figures

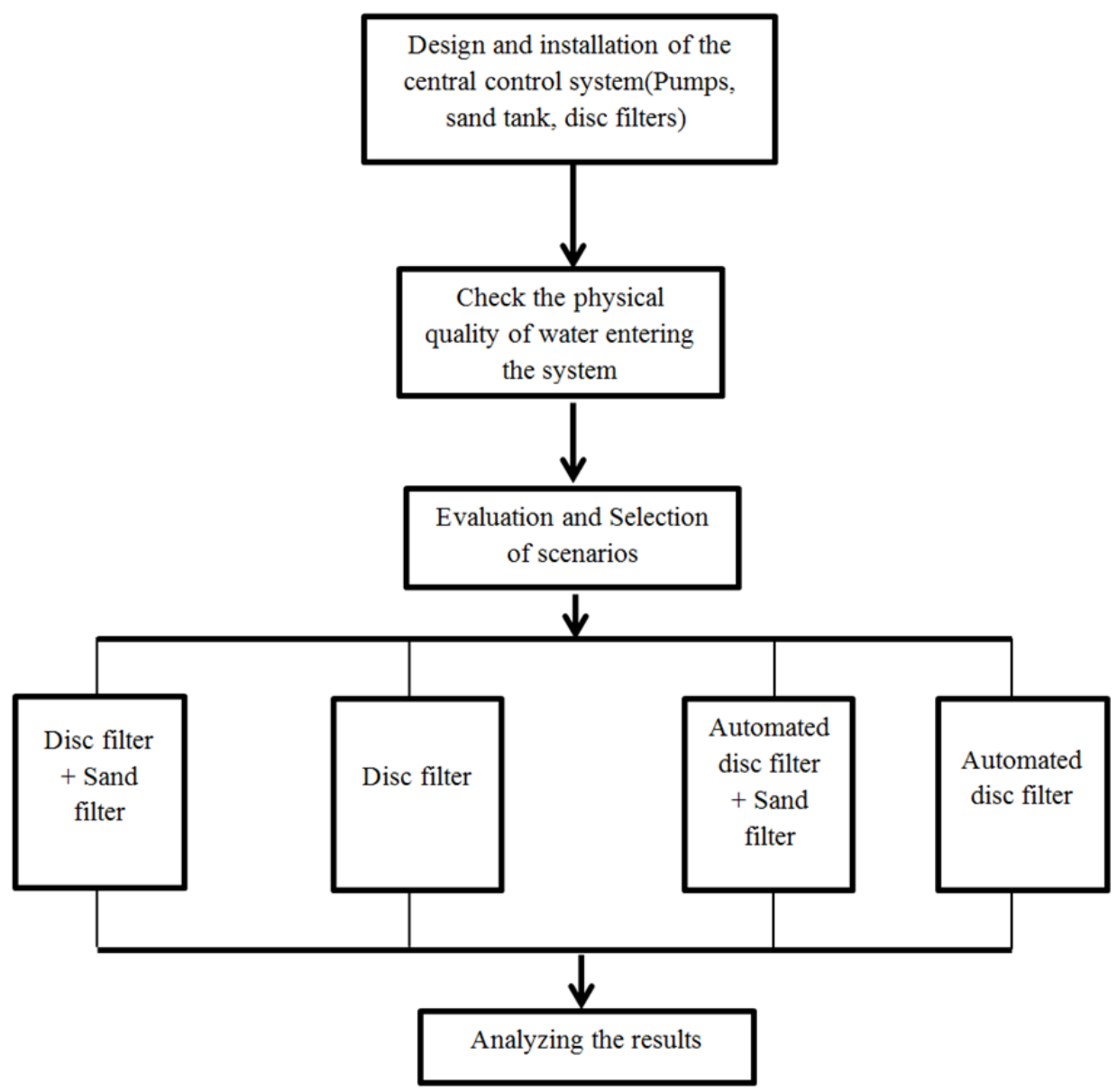

Figure 1. Flowchart of steps of experiments

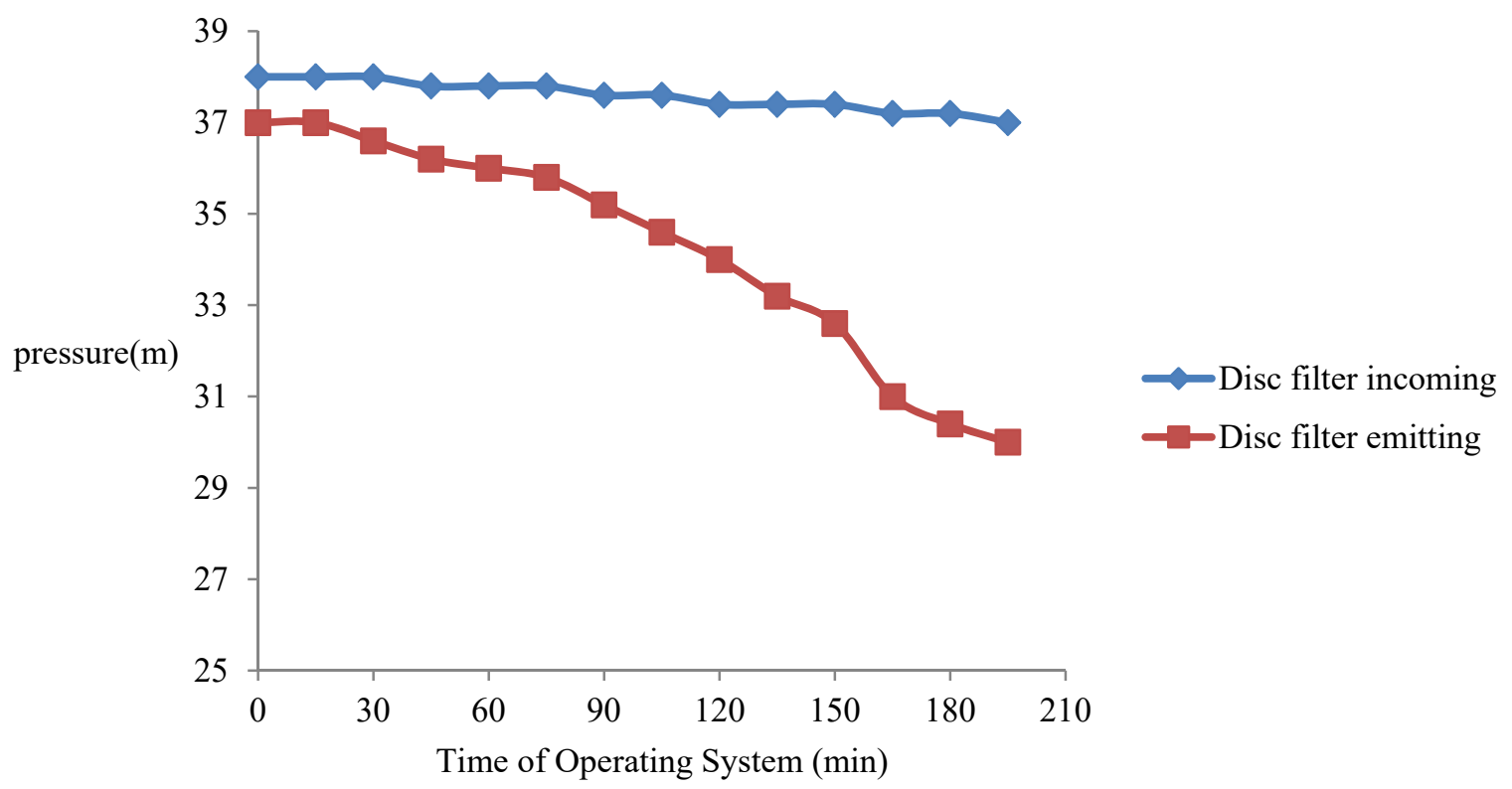

Figure 2. The blockage duration of disc filters with sand filter in irrigation water quality with moderate 


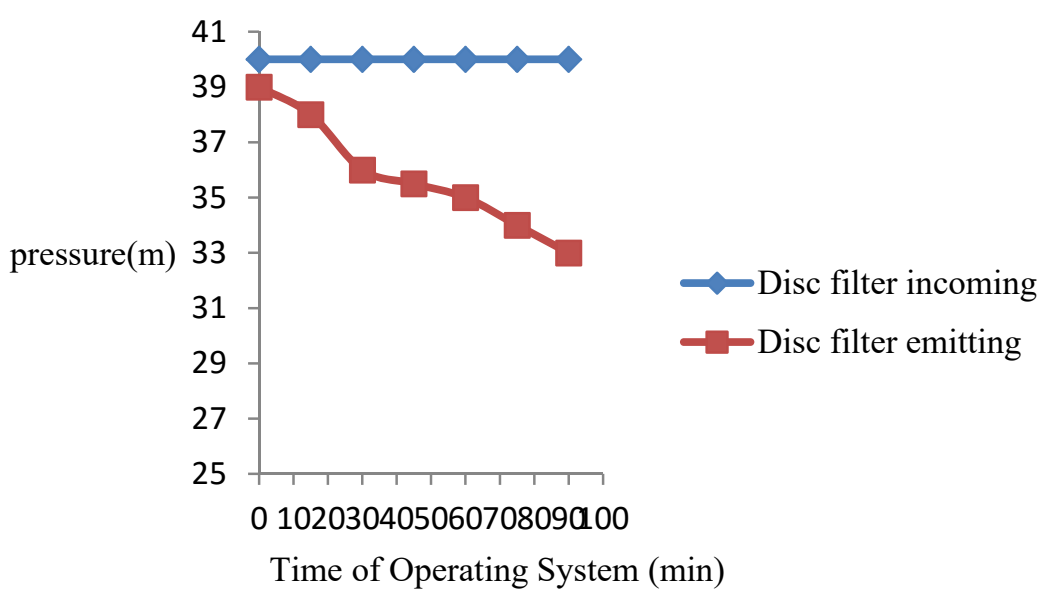

Figure 3. The blockage duration of disc filters without sand filter in irrigation water quality with moderate

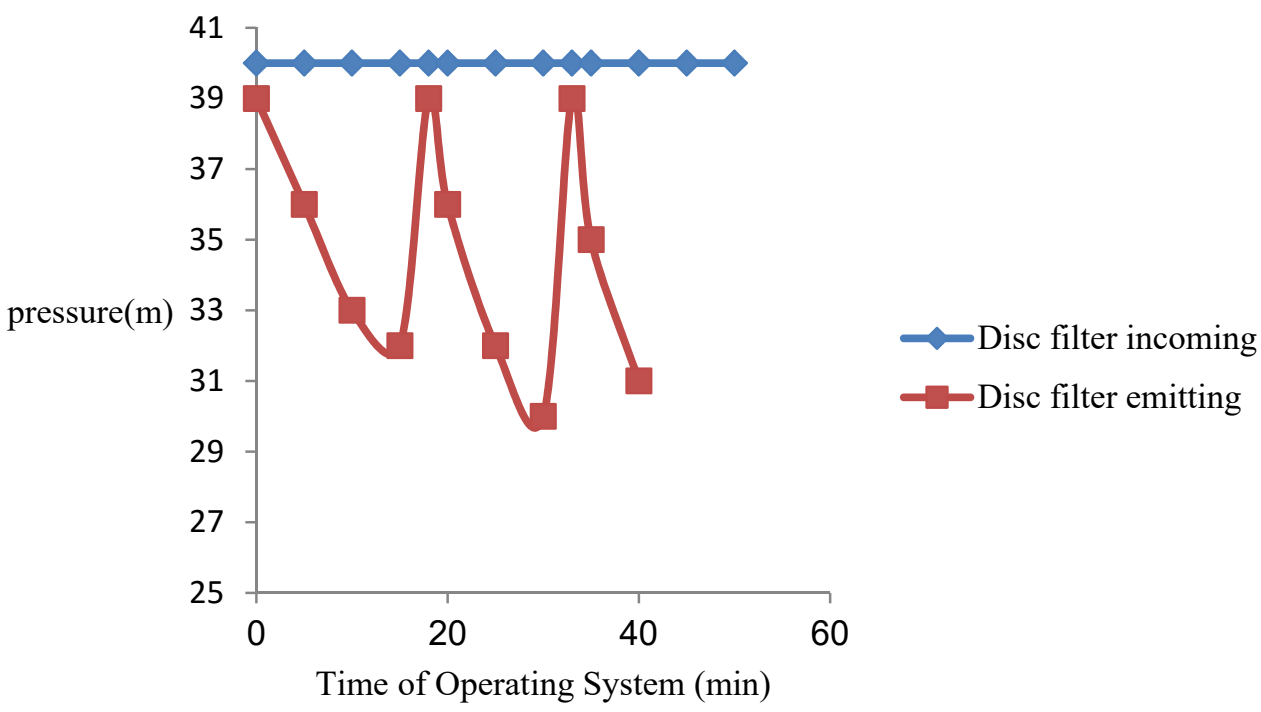

Figure 4. The blockage duration of disc filters without sand filter in irrigation water quality with severe

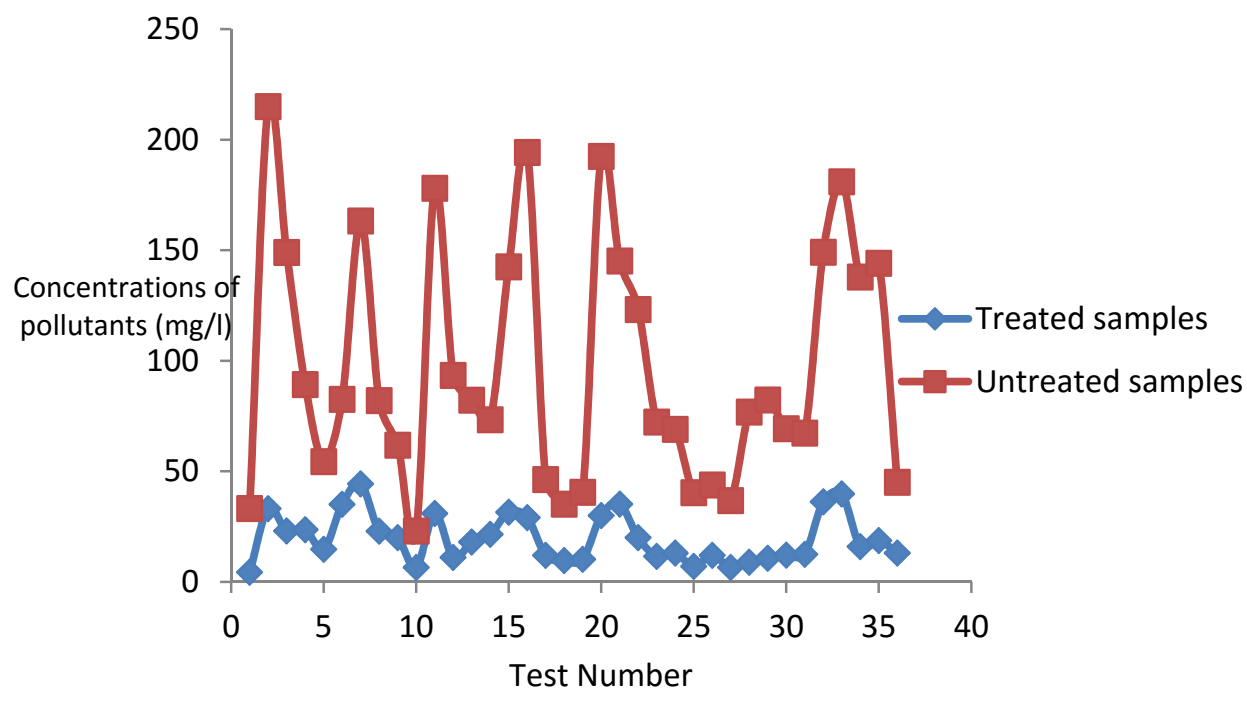

Figure 5. The amount of irrigation water treatment by filtration system 
Table 1. The blockage duration of disc filters without sand filter in irrigation water quality with slight

\begin{tabular}{lll}
\hline $\begin{array}{c}\text { Time of } \\
\text { Operating System } \\
(\mathrm{min})\end{array}$ & $\begin{array}{c}\text { Inlet pressure of disc } \\
\text { filter }(\mathrm{m})\end{array}$ & $\begin{array}{c}\text { The output pressure disc } \\
\text { filter }(\mathrm{m})\end{array}$ \\
\hline 0 & 40 & 39 \\
15 & 40 & 39 \\
30 & 40 & 39 \\
45 & 40 & 39 \\
60 & 40 & 38.8 \\
75 & 40 & 38.8 \\
90 & 40 & 38.8 \\
105 & 40 & 38.6 \\
120 & 40 & 38.6 \\
135 & 40 & 38.4 \\
150 & 40 & 38.2 \\
165 & 40 & 37.6 \\
180 & 40 & 37.2 \\
195 & 40 & 36.8 \\
210 & 40 & 36.2 \\
225 & 40 & 35.8 \\
240 & 40 & 35.4 \\
255 & 40 & 34.8 \\
270 & 40 & 34.4 \\
285 & 40 & 34 \\
300 & 40 & 33.8 \\
\hline
\end{tabular}

Table 2. The blockage duration of disc filters with sand filter in irrigation water quality with slight

\begin{tabular}{ccc}
\hline $\begin{array}{c}\text { Time of Operating } \\
\text { System }(\mathrm{min})\end{array}$ & $\begin{array}{c}\text { Inlet pressure of } \\
\text { disc filter }(\mathrm{m})\end{array}$ & $\begin{array}{c}\text { The output pressure } \\
\text { disc filter }(\mathrm{m})\end{array}$ \\
\hline 0 & 39 & 38 \\
15 & 39 & 38 \\
30 & 39 & 38 \\
45 & 39 & 38 \\
60 & 39 & 38 \\
75 & 39 & 38 \\
90 & 39 & 37.8 \\
105 & 39 & 37.8 \\
120 & 39 & 37.6 \\
135 & 39 & 37.4 \\
150 & 39 & 37.2 \\
165 & 38.8 & 36.6 \\
180 & 38.8 & 36.2 \\
195 & 38.6 & 35.8 \\
210 & 38.4 & 35.2 \\
215 & 38.4 & 34.8 \\
230 & 38.4 & 34.4 \\
245 & 38.4 & 33.8 \\
260 & 38.2 & 33.4 \\
275 & 38.2 & 33 \\
290 & 38.2 & 32.8 \\
305 & 38 & 32.4 \\
\hline
\end{tabular}


Table 3. Criteria for evaluating the "plugging potential" of micro-irrigation water sources

\begin{tabular}{llll}
\hline \multicolumn{4}{c}{ Pluggin hazard based on concentration } \\
\hline factor & Slight (mg/l) & Moderate $(\mathrm{mg} / \mathrm{l})$ & Severe $(\mathrm{mg} / \mathrm{l})$ \\
physical, suspende, solids, algae & $<50$ & $50-100$ & $>100$ \\
\hline
\end{tabular}

Table 4. Results of experiments

\begin{tabular}{|c|c|c|c|c|c|c|c|c|c|}
\hline & \multicolumn{9}{|c|}{ Concentrations of pollutants $(\mathrm{mg} / \mathrm{l})$} \\
\hline & \multicolumn{3}{|c|}{ Slight $(<50)$} & \multicolumn{3}{|c|}{ Moderate(50-100) } & \multicolumn{3}{|c|}{ Severe $(>100)$} \\
\hline Scenario & $\begin{array}{c}\text { blockage } \\
\text { duration } \\
\text { (min) }\end{array}$ & $\begin{array}{l}\text { water } \\
\text { flow } \\
\text { loss } \\
(1 / \mathrm{s})\end{array}$ & $\begin{array}{l}\text { percent } \\
\text { of } \\
\text { treatment }\end{array}$ & $\begin{array}{c}\text { blockage } \\
\text { duration } \\
\text { (min) }\end{array}$ & $\begin{array}{l}\text { water } \\
\text { flow } \\
\text { loss } \\
(1 / \mathrm{s})\end{array}$ & $\begin{array}{l}\text { percent } \\
\text { of } \\
\text { treatment }\end{array}$ & $\begin{array}{c}\text { blockage } \\
\text { duration } \\
\text { (min) }\end{array}$ & $\begin{array}{l}\text { water } \\
\text { flow } \\
\text { loss } \\
(1 / \mathrm{s})\end{array}$ & $\begin{array}{l}\text { percent } \\
\text { of } \\
\text { treatment }\end{array}$ \\
\hline $\begin{array}{c}\text { Disc filter } \\
+ \text { sand } \\
\text { filter }\end{array}$ & 195 & 0.11 & $68 \%$ & 90 & 0.22 & $72 \%$ & 75 & 0.17 & $82.50 \%$ \\
\hline $\begin{array}{l}\text { Disc filter } \\
\text { Auto disc }\end{array}$ & 150 & 0.6 & $67.80 \%$ & 90 & 0.42 & $77.71 \%$ & 35 & 0.75 & $78 \%$ \\
\hline $\begin{array}{l}\text { filter }+ \\
\text { Sand } \\
\text { filter }\end{array}$ & 255 & 0.6 & $71 \%$ & 150 & 0.6 & $88 \%$ & 60 & 0.8 & $78 \%$ \\
\hline $\begin{array}{c}\text { Auto disc } \\
\text { filter }\end{array}$ & 195 & 0.2 & $69.30 \%$ & 135 & 0.22 & $83 \%$ & 20 & 0.3 & $62.30 \%$ \\
\hline
\end{tabular}

Table 5. Filter performance in different qualities irrigation water

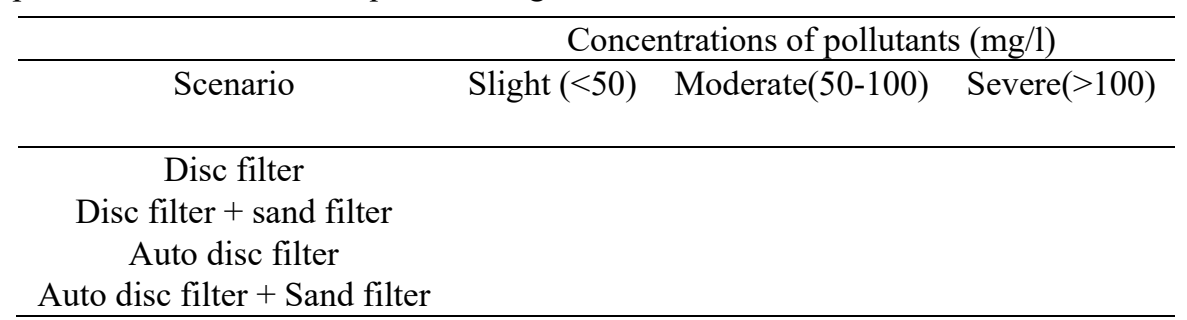

\section{Copyrights}

Copyright for this article is retained by the author(s), with first publication rights granted to the journal.

This is an open-access article distributed under the terms and conditions of the Creative Commons Attribution license (http://creativecommons.org/licenses/by/3.0/). 